\title{
Risk factors and incidence of contrast-induced acute kidney injury associated with diagnostic or interventional coronary angiography
}

\author{
Abhishek Maskey'", Ram Chandra Kafle', Sudip Lamsal²
}

${ }^{1}$ Associate professor, Department of Medicine, Manipal Teaching Hospital, Pokhara, Nepal

${ }^{2}$ Resident, Department of medicine, Manipal Teaching Hospital, Pokhara, Nepal

Keywords: acute kidney injury, contrast media, coronary intervention

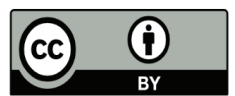

This work is licensed under a Creative Commons Attribution 4.0 Unported License.

\begin{abstract}
Background and Aims: Coronary angiography/ interventions depend on iodinated contrast media (CM) and consequently pose risk of contrast-induced acute kidney injury (CI-AKI). This is an important complication that accounts for a significant number of cases of hospital-acquired kidney injury, with adverse effects on prognosis and health care. This study aimed to assess incidence and evaluate risk factor $\mathrm{Cl}-\mathrm{AKI}$ associated with diagnostic or interventional coronary angiography.

Methods: A prospective cross sectional observational hospital based study was conducted. All patients undergoing percutaneous coronary angiography in Manipal Teaching Hospital from May 1, 2019 to April 31, 2020 were included in this study. Appropriate statistical tests were used to analyse results and $\mathrm{P}<0.05$ was considered statistically significant.

Results: We evaluated a total of 155 patients. Among them, $90(58 \%)$ were male and $65(42 \%)$ female. The mean age of patients was $62.74 \pm 13.9$ years. Overall incidence of contrast induced acute kidney injury was $15.48 \%$. Cl-AKI was observed to be more common in patient with advance age and diabetes. Apart from advance age and diabetes, none of the other conventional risk factors such as hypertension, anaemia, volume of contrast, baseline chronic kidney disease found to have a significant association with incidence of $\mathrm{Cl}-\mathrm{AKI}$. None of the patients in our study required renal replacement therapy, and there was no mortality.
\end{abstract}

Conclusion: The overall incidence of $\mathrm{Cl}-\mathrm{AKI}$ after coronary intervention in this study is high. Patients with advance age and diabetes were at high risk of $\mathrm{Cl}-\mathrm{AKI}$.
Introduction

Contrast-induced acute kidney injury (Cl-AKI) is a transient impairment of renal function which occurs after intravascular administration of iodinated contrast media. In the past, $\mathrm{Cl}$ AKI was considered to be a mild state with asymptomatic and transient elevations in serum creatinine values. However, recent studies have demonstrated that both short term and long-term mortality rates have been found to be significantly higher in patients with $\mathrm{Cl}-\mathrm{AKI}$ compared to patients without $\mathrm{Cl}-\mathrm{AKI} .{ }^{1} \mathrm{Cl}-\mathrm{AKI}$ is multifactorial, being dependent on patient-related and contrastrelated risk factors. Among the patient-related factors, the most important is the baseline renal function: the incidence of $\mathrm{Cl}-\mathrm{AKI}$ ranges from $2 \%$ in patients with normal renal function to $30-40 \%$ in patients with creatinine $>2 \mathrm{mg} / \mathrm{dll}^{2-4}$ Other important risk factors of $\mathrm{Cl}-\mathrm{AKI}$ are diabetes mellitus and advanced age. Anemia due to periprocedural bleeding may also contribute the risk for $\mathrm{Cl}-\mathrm{AKI}$ development, according to the decrease in hemoglobin levels. ${ }^{5}$ Moreover, heart failure and hemodynamic instability such as periprocedural hypotension and use of intra-aortic balloon pump have shown to be associated with an increased risk of Cl-AKI. ${ }^{6}$ Very few studies have been conducted in our country so far.

\footnotetext{
${ }^{*}$ Corresponding Author

Dr. Abhishek Maskey, Associate Professor

Department of medicine, Manipal Teaching Hospital, Pokhara, Nepal.
} Email: maskey21@hotmail.com 
Therefore, we conducted prospective cross sectional observational study to assess incidence and evaluate risk factors of $\mathrm{Cl}-\mathrm{AKI}$ associated with diagnostic or interventional coronary angiography.

\section{METHODS}

This is prospective cross sectional observational hospital based study conducted in Manipal Teaching Hospital, Pokhara, Nepal. All patients undergoing percutaneous coronary angiography from May 1, 2019 to April 31, 2020 were included in this study. The absolute amount of contrast media was recorded after each procedure. Laboratory data including pre- and post-procedural serum creatinine, glucose, serum sodium, serum potassium, and baseline hemoglobin were collected. Serum creatinine values were measured before the procedure for the baseline value and at 48 hours and 5 days. All patients were hydrated adequately as per the standard protocol, and no nephrotoxic drugs were used in them post contrast exposure. ${ }^{7}$

\section{Clinical Definitions:}

$\mathrm{Cl}-\mathrm{AKI}$ was defined as an increase of $>25 \%$ or $>0.5 \mathrm{mg} / \mathrm{dl}$ in prepercutaneous coronary intervention $(\mathrm{PCl})$ serum creatinine at or after $48 \mathrm{~h}$ after PCl. ${ }^{8}$ Data were entered on MS XP sheet and then converted to SPSS 20 version for statistical analysis. Continuous variables were expressed as mean, standard deviation (SD), and categorical data were presented as absolute values and percentages.

data derived from the absolute total score for each parameters. Degree of freedom was also reported with Chi-square, Effect size was reported with Cramer's V. P-value of $<0.05$ was concluded as being statistically significant. For the absolute total score of the parameters, mean ranks were calculated and analysis was done with Mann-Whitney U test.

\section{Results:}

We evaluated a total of 155 patients. Among them, 90 (58\%) were male and 65 (42\%) female. The mean age of patients was $62.74 \pm$ 13.9 years. Baseline characteristics of the patients are depicted in Table -1.

Table-2 showed twenty-four (15.48\%) patients developed $\mathrm{Cl}$ AKI in the entire study population. Table-3 provides the detailed features of patient with $\mathrm{Cl}$ - AKI. Briefly, $\mathrm{Cl}-\mathrm{AKI}$ was observed to be more common in advance age group of more than 70 years than age group less than 70 year $(P=0.045)$. Similarly, $\mathrm{Cl}-\mathrm{AKI}$ was found to occur more common in diabetics than in those without diabetes $(P=0.027)$. Hypertension, anaemia, baseline creatinine clearance was not observed to have an increased incidence of $\mathrm{Cl}$ AKI compared to rest of the population.

Descriptive analysis of the volume of contrast was also done to determine the role of volume of CM in the occurrence of Cl-AKI. The mean volume of contrast given to patient in our study was $96.8 \pm 28.8 \mathrm{ml}$. Patient who underwent intervention was given higher volume $(120 \pm 23.2) \mathrm{ml}$ of CM compared to those who underwent diagnostic angiography $(70 \pm 12.6 \mathrm{ml})$. However, the difference in volume of contrast administered to Cl-AKI group (104 $\pm 25 \mathrm{ml}$ ) was not statistically significant as compared to that of non $\mathrm{Cl}-\mathrm{AKI}(95 \pm 16 \mathrm{ml})$ group $(\mathrm{P}=0.33)$. None of the patient in our study required renal replacement therapy and there was no mortality.

\begin{tabular}{|r|r|r|r|}
\hline \multicolumn{4}{|c|}{ Table 1. Characteristics of patients of study population } \\
\hline & \multicolumn{1}{c|}{ Male } & \multicolumn{1}{c|}{ Female } & \multicolumn{1}{c|}{ Total } \\
\hline & $31.02 \pm 13.31$ & $27.81 \pm 7.87$ & 0.06 \\
\hline Number & 90 & 65 & 155 \\
\hline & $23.91 \pm 5.87$ & $23.67 \pm 4.9$ & 0.43 \\
\hline Age (yrs) & $63.06 \pm 13.7$ & $62.32 \pm 14.18$ & $62.74 \pm 13.92$ \\
\hline & 2.8 & 5.5 & 0.168 \\
\hline HTN & $42(46.6 \%)$ & $21(32.30 \%)$ & $63(40.65 \%)$ \\
\hline DM & $17(18.8 \%)$ & $14(21.54 \%)$ & $31(20 \%)$ \\
\hline Anemia & $63(70 \%)$ & $44(67.69 \%)$ & $107(69.03 \%)$ \\
\hline eGFR<60 ml & $11(12.2 \%)$ & $12(18.46 \%)$ & $23(14.84 \%)$ \\
\hline CIAKI & $12(13.33 \%)$ & $12(18.46 \%)$ & $24(15.45 \%)$ \\
\hline
\end{tabular}

\begin{tabular}{|c|c|c|c|}
\hline \multicolumn{3}{|c|}{ Table 2. Frequency of Cl- AKI in study population } \\
\hline & $\begin{array}{c}\text { Number } \\
(\%)\end{array}$ & $\begin{array}{c}\text { Creatinine at } \\
\text { Admission } \\
\text { (before } \\
\text { Procedure) }\end{array}$ & $\begin{array}{c}\text { Creatinine at } \\
\text { 48hrs }\end{array}$ \\
\hline $\begin{array}{c}\text { Patients with } \\
\text { Cl-AKI }\end{array}$ & $24(15.48)$ & $0.9042 \pm$ & $1.7250 \pm 1.44$ \\
& & 0.49 & \\
\hline $\begin{array}{c}\text { Patients without } \\
\text { Cl-AKI }\end{array}$ & $131(84.52)$ & $0.9388 \pm$ & $0.9840 \pm 0.64$ \\
& & 0.48 & \\
\hline
\end{tabular}

\begin{tabular}{|c|c|c|c|}
\hline \multicolumn{4}{|c|}{ Table- 3: Risk factors for contrast induced- Acute kidney injury } \\
\hline & & Cl-AKI & P value \\
\hline Age & $\geq 70 y r s$ & $13(23.21)$ & 0.045 \\
\hline & $<70 y r s$ & $11(11.11)$ & \\
\hline Gender & Male & $12(13.33)$ & 0.384 \\
\hline & Female & $12(18.46)$ & \\
\hline DM & Present & $9(29)$ & 0.027 \\
\hline & Absent & $15(12.09)$ & \\
\hline HTN & Present & $12(19.05)$ & 0.310 \\
\hline & Absent & $12(13.04)$ & \\
\hline Anemia & Present & $15(14.02)$ & 0.452 \\
\hline & Absent & $9(18.7)$ & \\
\hline eGFR & $<60$ & $5(21.73)$ & 0.319 \\
\hline & $\geq 60$ & $19(14.39)$ & \\
\hline
\end{tabular}

\section{Discussion:}

Our study showed $15.48 \%$ incidence of $\mathrm{Cl}$-AKI in patient undergoing coronary angiography. Some studies showed lower incidence ${ }^{9-12}$ of $\mathrm{Cl}-\mathrm{AKI}$ than our study and some studies were similar. ${ }^{13-16}$ But there is wide variation in reported incidence of AKI in the world ${ }^{17}$. This is assumed to be caused by lack of standardization, timing of creatinine measured, baseline characteristics and type of contrast used. Cho et al found overall incidence of $14.5 \%$ in their study among 510 patients who underwent cardiac catheterization. ${ }^{14}$ Similarly, study done by Chong $E$ et al found to have high incidence of $11.5 \%$ despite the prophylactic measures were taken. ${ }^{15}$ Marenzi et al showed very 
high incidence of $19 \% \mathrm{Cl}-\mathrm{AKI}$ in patient undergoing coronary intervention. ${ }^{16}$ Contrast to our study, Jeon et al, Sharma et al and Rihal et al, showed low incidence of $\mathrm{Cl}-\mathrm{AKI}$ in their study. ${ }^{9,10,12}$

Another significant observation of our study is the self-limiting course of the $\mathrm{Cl}-\mathrm{AKI}$ in all patients without the requirement of renal replacement therapy. The main reason for this observation could be that none of our patients had moderate to severe renal insufficiency and also the severity of $\mathrm{Cl}-\mathrm{AKI}$ was mild. A similar observation was made by Lautin et $\mathrm{al}^{18}$ but this is in contrast to previous studies of Cl-AKI. ${ }^{19,20}$ Multiple factors could explain this observation including careful patient selection, minimal use of $\mathrm{CM}$, avoidance of nephrotoxic drugs, and ensuring proper hydration in the post-procedure period.

Advanced age has been demonstrated to be a risk factor for the occurrence of $\mathrm{Cl}-\mathrm{AKI} .{ }^{21}$ In this study, the incidence of $\mathrm{Cl}-\mathrm{AKI}$ in patient's $\geq 70$ years was $23.21 \%$ vs $11.11 \%$ in age less than 70 years $(P=0.045)$. The result was consistent with the finding of Palli $E$ et al. ${ }^{22}$ Study by Marenzi et al. and Mehran et al. showed $\geq 70$ years of age appeared to be an independent predictor of $\mathrm{Cl}-\mathrm{AKI}{ }^{16,17} \mathrm{The}$ reasons for this higher risk of $\mathrm{Cl}-\mathrm{AKI}$ in advance age group are probably multifactorial, including aging kidney, atherosclerosis, presence of multi-vessel disease, and more difficult vascular access due to tortuosity and calcification of the vessels requiring relatively larger amounts of contrast.

Besides advance age, diabetes mellitus is another well-recognized independent risk factor for CI-AKI.23 This study showed 29\% of diabetic patients developed $\mathrm{Cl}$-AKI. Our study is also consistent with that of many studies, who found the presence of diabetes to be a significant risk factor for the occurrence of Cl-AKI. ${ }^{24-26}$ Rahman et al showed $36 \%$ of diabetic patient developed $\mathrm{Cl}-\mathrm{AKI}^{27}$ In contrast to our study, Parfrey et al. in a prospective trial of patients with diabetes, showed that none of 85 patients with diabetes and normal renal function developed clinically significant renal impairment. ${ }^{28}$ Importantly, in diabetic patients with preserved renal function and the absence of other risk factors, the rates of $\mathrm{Cl}$ AKI are usually comparable to those of a non-diabetic population, while clinically important $\mathrm{Cl}-\mathrm{AKI}$ usually occurs in a subset of diabetics with underlying renal insufficiency. ${ }^{29,30}$

In this study, apart from advance age and diabetes, none of the other conventional risk factors such as hypertension, anaemia, volume of contrast, baseline chronic kidney disease were found to have a significant association with incidence of $\mathrm{Cl}$-AKI. This could be due to the small number of patient in our study. lakovou et al reported female gender is an independent predictor of CIN development after coronary intervention. ${ }^{31}$ Wen-hua et al showed anaemia is associated with higher incidence of $\mathrm{Cl}-\mathrm{AKI}$ with moderate renal insufficiency. ${ }^{32}$ Patients with $\mathrm{PCl}$ did not have a higher incidence of $\mathrm{Cl}-\mathrm{AKI}$ despite receiving a higher $\mathrm{CM}$ dose due to the smaller volume of CM used than in other studies. This observation emphasizes that pre-existing renal compromise and comorbid ailments play an important role in the development of $\mathrm{Cl}-\mathrm{AKI}$ other than the type and quantity of $\mathrm{CM}^{33}$

Our study has few limitations including small sample size, single study center, and limited study period. Less patients with compromised baseline renal function were exposed to contrast. This might act as selection bias during the study.

In conclusion, $\mathrm{Cl}-\mathrm{AKI}$ is a potential risk factor for all patients undergoing diagnostic or interventional coronary angiography. Our study showed overall incidence of $\mathrm{Cl}-\mathrm{AKI}$ is high. Patient with advance age and diabetes significantly increase the incidence of Cl-AKI.

Publication History:

Date of submission: Arpil 23, 2020

Date of acceptance: May 22, 2020

\section{References}

1. Rudnick M, Feldman H. Contrast-induced nephropathy: what are the true clinical consequences? Clin J Am Soc Nephrol 2008;3:263-72.

2. McCullough PA, Adam A, Becker CR, et al. Epidemiology and prognostic implications of contrast-induced nephropathy. Am J Cardiol 2006;362:5-13.

3. McCullough PA, Wolyn R, Rocher LL, et al. Acute renal failure after coronary intervention: Incidence, risk factors, and relationship to mortality. Am J Med 1997;103:368-75.

4. Stacul F, Molen AJ, Reimer P, et al. Contrast induced nephropathy: Updated ESUR contrast media safety committee guidelines. Eur Radiol 2011: 2527-41.

5. Ohno $\mathrm{Y}$, Maekawa $\mathrm{Y}$, Miyata $\mathrm{H}$, et al. Impact of periprocedural bleeding on incidence of contrast induced acute kidney injury in patients treated with percutaneous coronary intervention. J Am Coll Cardiol 2013;286:1260-6.

6. Dangas G, lakovou I, Nikolsky E, et al. Contrast-induced nephropathy after percutaneous coronary interventions in relation to chronic kidney disease and hemodynamic variables. Am J Cardiol 2005:13-19.

7. Trivedi HS, Moore H, Nasr S, et al. A randomized prospective trial to assess the role of saline hydration on the development of contrast nephrotoxicity. Nephron Clin Pract 2003;93:29-34.

8. National Kidney Foundation. K/DOQI: Clinical practice guidelines for chronic kidney disease: evaluation, classification, and stratification. Am J Kidney Dis 2002;39:S1-266.

9. Jeon J, Kim S, Yoo H, Kim K, et al. Risk Prediction for ContrastInduced Nephropathy in Cancer Patients Undergoing Computed Tomography under Preventive Measures. Journal of Oncology 2019:210-7.

10. Sharma SK, Dubey L, Laudary S, et al. Incidence and predictors of contrast Induced Nephropathy after coronary intervention at College of Medical Sciences-Teaching Hospital, Bharatpur. Nepalese Heart Journal 2014;11:3-11.

11. Tsai TT, Patel UD, Chang TI, et al. Contemporary incidence, predictors, and outcomes of acute kidney injury in patients undergoing percutaneous coronary interventions: insights from the NCDR Cath-PCI Registry. J Am Coll Cardiol Intv 2014;7:1-9.

12. Rihal CS, Textor SC, Grill DE, et al. Incidence and prognostic importance of acute renal failure after percutaneous coronary intervention. Circulation 2002; 105:2259-64

13. Azzalini L, Vilca LM, Lombardo F, et al. Incidence of contrastinduced acute kidney injury in a large cohort of all-comers undergoing percutaneous coronary intervention: Comparison of five contrast media. Int J Cardiol. 2018;273:69-73.

14. Cho JY, Jeong MH, Park SH, et al. Effect of contrast-induced nephropathy on cardiac outcomes after use of nonionic isosmolar contrast media during coronary procedure. Journal 
of Cardiology 2010;56:300-6.

15. Chong E, Shen L, Poh KK, et al. Risk scoring system for prediction of contrast-induced nephropathy in patients with pre-existing renal impairment undergoing percutaneous coronary intervention. Singapore Med J 2012;53:164-9 [PMID: 22434288]

16. Marenzi G, Lauri G, Assanelli E, et al. Contrast-induced nephropathy in patients undergoing primary angioplasty for acute myocardial infarction. J Am Coll Cardiol 2004; 44:1780-5 [PMID: 15519007 DOI: 10.1016/j.jacc.2004.07.043]

17. Mehran R, Aymong ED, Nikolsky E, et al. A simple risk score for prediction of contrast-induced nephropathy after percutaneous coronary intervention: development and initial validation. J Am Coll Cardiol 2004;44:1393-9.

18. Lautin EM, Freeman NJ, Schoenfeld AH, et al. Radiocontrastassociated renal dysfunction: A comparison of lowerosmolality and conventional high-osmolality contrast media. AJR Am J Roentgenol 1991;157:59-65.

19. Solomon RJ, Mehran R, Natarajan MK, et al. Contrast-induced nephropathy and long-term adverse events: Cause and effect? Clin J Am Soc Nephrol 2009;4:1162-9.

20. Roghi A, Savonitto S, Cavallini C, et al. Impact of acute renal failure following percutaneous coronary intervention on longterm mortality. J Cardiovasc Med 2008;9:375-81.

21. Toprak O, Cirit M. Risk factors for contrastinduced nephropathy. Kidney Blood Press Res 2006;29:84-93.

22. Palli E, Makris D, Papanikolaou, et al. Contrast-Induced Nephropathy in Aged Critically III Patients. Oxid Med Cell Longev. 2014; doi: 10.1155/2014/756469

23. Kolonko A, Wiecek A. Contrast-associated nephropathy: old clinical problem and new therapeutic perspectives. Nephrol Dial Transplant 1998;13:803-6

24. lakovou I, Dangas G, Mehran R, et al. Impact of gender on the incidence and outcome of contrast-induced nephropathy after percutaneous coronary intervention. J Invasive Cardiol.
$2003 ; 15: 18-22$

25. Bartel DP. MicroRNAs: genomics, biogenesis, mechanism, and function. Cell 2014;116: 281-97.

26. Mandal A, Paudel M S, Kafle $P$, et al. Contrast-induced Nephropathy Following Percutaneous Coronary Intervention at a Tertiary Cardiac Center in Nepal. Cureus 201810(9): e3331. DOI 10.7759/cureus.3331

27. Rahman MM, Haque HS, Banerjee SK, et al. Contrast induced nephropathy in diabetic and non-diabetic patients during coronary angiogram and angioplasty. Mymensingh Med J. 2010;19:372-6.

28. Parfrey PS, Griffiths SM, Barrett BJ, et al. Contrast materialinduced renal failure in patients with diabetes mellitus, renal insufficiency, or both. N Engl J Med 1989;320:143-53

29. Lasser EC, Lyon SG, Berry CC. Reports on contrast media reactions: analysis of data from reports to the US Food and Drug Administration. Radiology 1997;203: 605-10

30. Nikolsky E, Mehran R, Turcot D et al. Impact of chronic kidney disease on prognosis of patients with diabetes mellitus treated with percutaneous coronary intervention. Am J Cardiol 2004;94:300-5

31. lakovou I, Dangas $G$, Mehran R, et al. Impact of gender on the incidence and outcome of contrast-induced nephropathy after percutaneous coronary intervention. J Invasive Cardiol 2003;15:18-22

32. Wen-hua Li, Dong-ye Li, Fei Han, et al. Impact of anemia on contrast-induced nephropathy $(\mathrm{CIN})$ in patients undergoing percutaneous coronary interventions. Int Urol Nephrol. 2013;45:1065-70

33. Brown JR, Robb JF, Block CA, et al. Does safe dosing of iodinated contrast prevent contrast-induced acute kidney injury? Circ Cardiovasc Interv 2010;3:346-50. 